\title{
STUDY OF RIVER CHANNEL MIGRATION AND IDENTIFICATION OF POTENTIAL SUGARCANE CULTIVATION AREA IN THE MOHANA-MACHELI WATERSHED USING REMOTE SENSING
}

\author{
D. Neupane ${ }^{1}$, P. Gyawali ${ }^{1}$, D. Tamang ${ }^{2}$ \\ ${ }^{1}$ Dept. of Geomatics Engineering, Kathmandu University, Dhulikhel Nepal - (dinesh.neupane5, pradeep2gyawali)@gmail.com \\ ${ }^{2}$ Mercy Corps Nepal, Lalitpur Nepal - dtamang@mercycorps.org
}

KEY WORDS: Lateral Shift, UTM, LULC, DEM, LANDSAT, Image Interpretation

\begin{abstract}
:
Channel migration becomes the main characteristic of major rivers of Mohana-Macheli watershed of western Nepal. Study of river channel migration of major rivers of watershed using freely available remote sensing show that the channel has shifted to as high as 1000 meters from the original river path over the span of 9 years (2009-2017). The channel migration directly affects the land use and it has direct effect on the flood plain settlements of the study area. Cultivation of sugarcane in sand area is one of the mitigating measures of flood effects and prevent river bank erosion. The study shows that the area of sand is changing disproportionately in the region. This paper presents an enhanced change detection method of river channel migration using remotely sensed images and identification of sand area using classification and interpretation technique.
\end{abstract}

\section{INTRODUCTION}

\subsection{Background}

With geographical and topographical complexity of the country Nepal is prone to various natural disasters like flood and landslide. The arrival of Rainy season (June-August) has significant effect in climate with higher chances of naturally occurring disasters like flood and landslides in various parts of the country including Kailali and Kanchanpur district of Far Western Nepal. The study of Mohana-Macheli watershed of far western Terai using Remote Sensing is to determine the area of sand cover and Lateral Shift of two rivers across different time series. The study includes detail analysis of hydrology of the Mohana and Macheli river watershed in order to determine the sandy area along the banks of river which could be potential areas for sugarcane cultivation.

Land cover data represents how much of a region is covered by various land cover types like forests, wetlands, impervious surfaces, agriculture, and other land and water types. Land use shows how people use the landscape - whether for development, conservation, or mixed uses. The different types of land cover can be used quite differently. Land cover can be determined by analysing satellite and aerial imagery. Land use cannot be determined from satellite imagery (OceanFacts, 2015). Land cover maps provide information to help managers best understand the current landscape. To see change over time, land cover maps for several different years are needed. With this information, we can evaluate past management decisions as well as gain insight into the possible effects of their current decisions before they are implemented. One of the most important functions of remote sensing data is the production of Land Use and Land Cover maps and thus can be managed through a process called image classification.

Image classification is the process of assigning land cover classes to pixels. A human analyst attempting to classify features in an image uses the elements of visual interpretation to identify homogeneous groups of pixels which represent various features or land cover classes of interest. Digital image classification uses the spectral information represented by the digital numbers in one or more spectral bands, and attempts to classify each individual pixel based on this spectral information (GIS Geography, 2018). This type of classification is termed spectral pattern recognition. In either case, the objective is to assign all pixels in the image to particular classes or themes (e.g. water, forest, barren land etc.). The resulting classified image is comprised of a mosaic of pixels, each of which belong to a particular theme, and is essentially a thematic"map" of the original image. Mainly two classification Techniques are used: viz. Supervised Classification and Unsupervised Classification.

In unsupervised classification, it first groups pixels into "clusters" based on their properties. In order to create "clusters", analysts use image clustering algorithms such as Kmeans and ISODATA. (Tandonline, 2017). For the most part, they can use this list of free remote sensing software to create land cover maps. The user can specify which algorism the software will use and the desired number of output classes but otherwise does not aid in the classification process. However, the user must have knowledge of the area being classified when the groupings of pixels with common characteristics produced by the computer have to be related to actual features on the ground.

Supervised Classification is based on the idea that a user can select sample pixels in an image that are representative of specific classes and then direct the image processing software to use these training sites as references for the classification of all other pixels in the image. Training sites (also known as testing sets or input classes) are selected based on the knowledge of the user. The user also sets the bounds for how similar other pixels must be to group them together. These bounds are often set based on the spectral characteristics of the training area, plus or minus a certain increment (often based on "brightness" or strength of reflection in specific spectral bands). The user also designates the number of classes that the image is classified into. Many analysts use a combination of supervised and unsupervised classification processes to develop final output analysis and classified maps. The workflow method for Supervised classification is given below: 


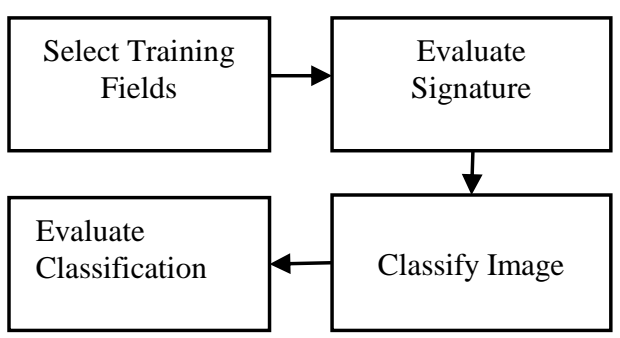

Fig:1 Working of Supervised classification

\subsection{Lateral Shift/River Channel Migration}

River channel migration is the geomorphological process that involves the lateral migration of an alluvial river channel across its floodplain. This process is mainly driven by the combination of bank erosion of and point bar deposition over time. When referring to river channel migration, it is typically in reference to meandering streams. In braided streams, channel change is driven by sediment transport (Datapages Archives, 1987).

Understanding the mechanisms and rates of bank erosion, accretion and lateral channel migration has fundamental significance, as well as results of this study which are applicable in the field of flood control and other natural disaster control and management and in different aspects of the environmental protection (Thorne 1982, Lawler 1993). Scientific and engineering interest for bank erosion, accretion and lateral channel shifting of Mohana and Macheli river has been increased for three main reasons. First, bank erosion plays an important role in control of channel stability. second, bank erosion has significant contribution to the sediment load, and third, destruction of flood plain land, land loss and land use changes is associated with serious bank erosion. The physical processes involved in river channel migration are: Bank Erosion and Point Bar Deposition.

As flow enters the bank of an alluvial river, the centrifugal force created by the bend instigates helicoidal flow, a corkscrew like pattern of flow, which drives the hydraulic action acting on the opposing bank. This is where the primary process in river channel migration of bank erosion occurs. Factors that limit the rate of bank erosion include the rate of deposition of the point bar, stream power, and the critical shear stress of the stream bed.

The sediment taken from the bank during the process of bank erosion is deposited on the opposing side of the channel fuelling the process called point bar deposition. The processes of point bar deposition and bank erosion are intertwined and in most cases the erosion rate of cut banks is equal to the deposition rate of point bars. In addition, point bars act as topographic obstructions once formed that further drive flow into the opposite bank, creating a positive feedback loop. This leads to the meanders of an alluvial river becoming more well defined over time (Seddepseq.co, 2015).

Avulsion has been defined as a rapid and spatially discontinuous shift of a river or a distributary channel to a new course on a lower part of a floodplain (Allen, 1965) and is considered a major fluvial hazard in large population centers (Jain and Sinha, 2004; Sinha, 2009). Avulsion commonly occurs when a reach of the river is at or near an 'avulsion threshold' (Jones and Schumm,1999) and such shifts in river course significantly influence its morphology, the water and sediment distribution in rivers, and the architecture of fluvial deposits (Törnqvist and Bridge, 2002; Jain and Sinha, 2003; Slingerland and Smith, 2004; Aslan et al., 2005; Stouthamer and Berendsen, 2007). Nepal with the complex geography and topography, natural disasters such as flood and landslide are the most frequent occurring hazards in the country. Following the monsoon season, there will be a number of water induced landslides in mountains, flash floods and floods in plain region of the Terai. (Adhikari et al.,2014).

The study of two rivers (Mohana and Macheli) in far western Terai provides a good opportunity to study bank erosion, river shifting /lateral shifting, we started analyzing these processes using available data suing Envi, GIS and MS-Exel. The availability of satellite images (i.e Landsat- 08 and Sential-2a), and GIS has opened up to possibility to research bank erosion, accretion and lateral channel migration. Worldwide, several different techniques have been used to quantify these processes. We choose two years' interval between 2009 to 2017 i.e. 2009,2011,2013,2015 and 2017.

\subsection{Causes of River Shifting in Nepal}

Nepal has very rough topography. It has steeper gradient in upper part then that of lower part. As the river slows down the sediment it has been carrying for miles begins to settle down at the river bottom. The river eats up its outer edges, widening its course. Over a long period, the deposit of sediment at the river bottom rises, forcing the river to change its course. Many rivers change its course in the lower course when it enters the lower part of region i.e. Terai plain region. However, in case of Mohana-Macheli river the change is more frequent. This is due to these factors: Gradient in the Upper course, Speed of water, Length of the middle course. In 2008 a heavy rainfall in far western region affected the mountain districts with a series of landslides and the Terai districts were affected by floods (Adhikary, 2013). All the rivers originating from the Churia hills overflowed with bank full discharges, eroded adjacent agricultural lands, deposited sands and silt on nearby houses, and inundated settlements for days. The East-West highway was eroded in two-three places in Kailali and Kanchanpur districts along with damages to irrigation projects, transmission lines, and other public and private infrastructure.

\section{STUDY AREA}

Mohana and Macheli river watershed extends between 80 degree 18 minute and 16.485 second $\mathrm{E}$ to 81 degree 14 minutes 13.08 seconds $\mathrm{E}$ and 28 degrees 22 minutes 11.761 seconds to 29 degrees 4 minutes 33.978 seconds N. It lies in Karnali zone of far western Nepal. It covers the whole area of Kailali district and has a catchment area of 2918.22 square kilometers. The elevation range is comprised between 140 to 1961 meter. The Mohana River is established as a boundary between Kailali and Kanchanpur District.Karnali and Mohana rivers are the major rivers of Kailal District and Karnali River being the longest river arising from hundreds of kilometres upstream in the Himalayas. Mohana and its tributaries like Godawari, Khutiya, Shivaganga, Gauriganga, Kandra, and Patharaiya arise from the Churia gaining most of their dry season flow from springs. These rivers are originating from the Churia range of Nepal which is composed of very fragile sediments. Similarly, Mahakali River which originates from the Himalayas, there are numerous rivers arising from Churia namely Jogbudha, 
Chaudhar, Radha, Siyali, Sonbhara, Banhara and Machheli in Kanchanpur District. Macheli river watershed is smaller compared to Mohana River and it has area of 784 square kilometres. The elevation range is 165 to 1950 meter.

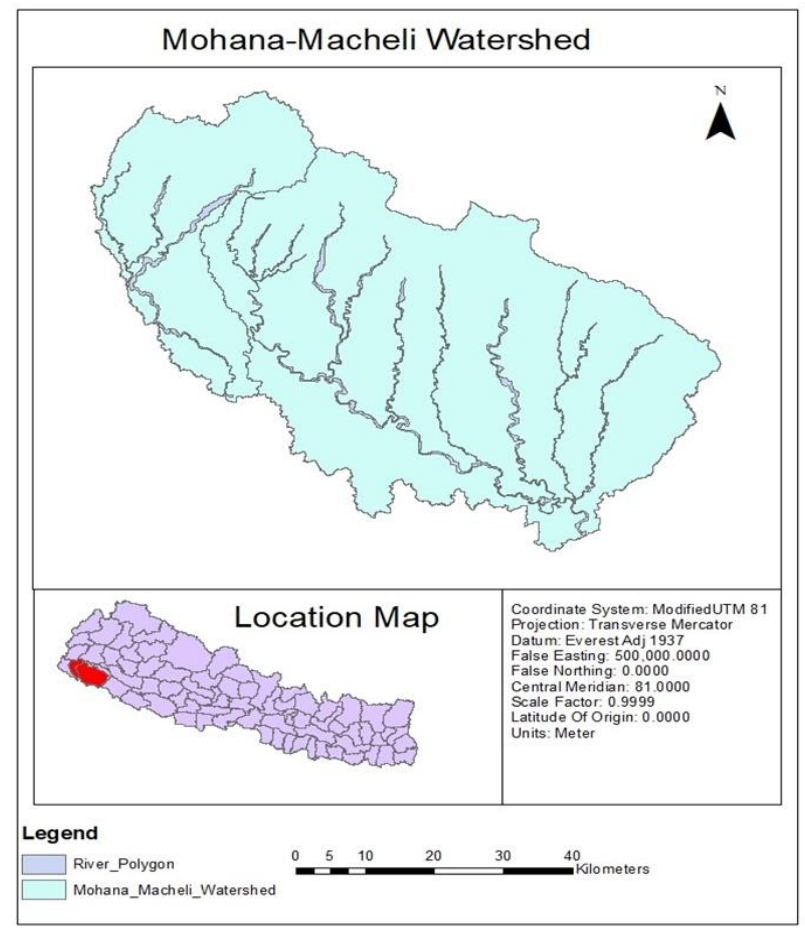

Fig 2: Study area (Mohana-Macheli Watershed Nepal)

\section{METHODOLOGY}

\subsection{Sand Cover Area and Change Detection}

The first stage of any remote sensing work is the image acquisition stage. After the image has been obtained, various methods of processing can be applied to the image. LANDSAT image for 2009, 2011, 2013 and 2015 were downloaded from official USGS database that is made freely available to use. The resolution of those images were 30 meters meaning that each pixel represented an area of 900 square meters. For the year 2017 Santenial Image with a resolution of 10 meters were used. The Landsat and Santenial images were geocorrected to the UTM projection. The raw Landsat images contain 7 layers, or bands, that correspond to reflectance received by the satellite sensors in various wavelength ranges.

\subsection{Resampling of Image Data}

Image data with different resolutions for different years is used so it is necessary to find a compromise between them. The lower resolution satellite images LANDSAT Satellite Images with $30 \mathrm{~m}$ resolution will be resampled to match the resolution of Santenial Images (10 m resolution).

\subsection{Land Cover Groups (Training Groups) and Signature Extraction}

The different land cover classes of the study area were grouped into five for easy analysis and assessment of change detection. The land cover classification includes Vegetation, Sandy Area, Settlement Area and Water Areas. The Vegetation area includes all of grassland and forest area. Water areas include rivers, ponds and streams. As the primary objective of the work is to identify the sand area suitable classes were made. "Training sites" are areas of known land cover, usually no more than 1000 square meters in size. [Hill, Kristina 2003]

Once the training sites were selected classification signature of each land cover classes were generated using ArcGIS Image Classification toolbar. Using the signature editor module in ArcGIS spectral signature were simultaneously extracted for each land use classes yielding 'signatures' for each training site within each class. Signatures within each class were then combined to obtain a single spectral signature range in 4dimensional space for each class.

\subsection{Image Classification}

Among various approaches of Image Classification, we will be using Supervised classification technique. The supervised technique has some advantage over the unsupervised one. In supervised approach useful information categories are distinct first, and then their spectral reparability is examined while in the unsupervised approach, the computer determines spectrally separable class, and then defines their information value. [H. I. Abdelkader, 2015]. The first supervised classification was conducted on Landsat and Santeniel images using the obtained signatures (i.e. Vegetation, Sandy Area, Settlement Area and Water Areas). The classification utilized the maximumlikelihood parametric rules in classification of individual pixels of Landsat and Santeniel images. This rule calculates the statistical probability of a pixel belonging to a particular class, based on the variance and covariance of the spectral signatures. The output from this process, termed the "Classified Image, "consisted of all 4 classes corresponding to the 4 signatures.

The accuracy assessment is a comparison of a classification with ROI or ground-truth data to evaluate how well the classification represents the real world. This is produced in a matrix table showing four different types of accuracies. However, Accuracy assessment requires that an adequate number of samples per map class be gathered when the classified results are compared with actual ground condition.

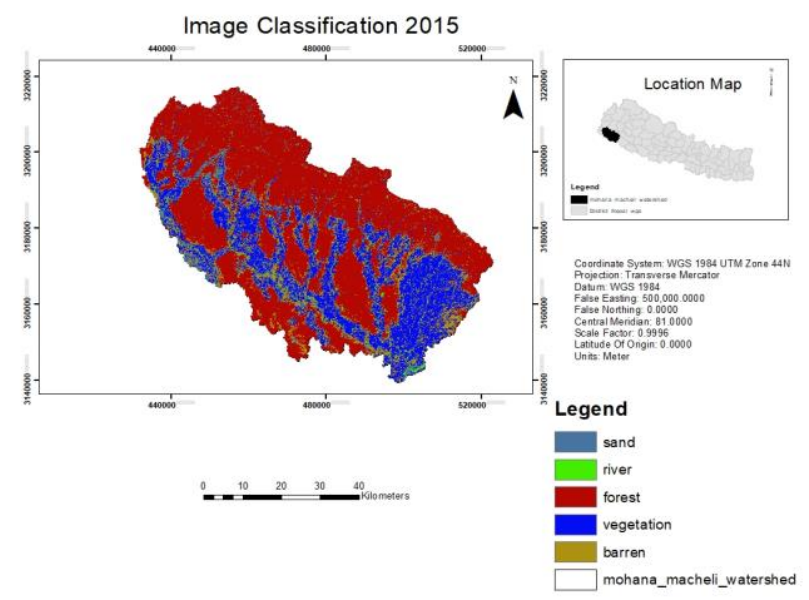

Fig 3: A portion of the final classified image, cantered on Mohana-Macheli watershed of 2015

\subsection{Identification of potential area for sugarcane cultivation}

The sand area in Mohana-Macheli watershed is undertaken by as the potential area for sugarcane cultivation areas to protect 
the future flooding. Total sand area of each year was calculated along with total sand area in each river for each year of study. Sand cover in newly formed local bodies was also calculated so that it becomes easier for to execute the mitigation measures.

\subsection{Determination of Change}

Image differencing for Land Cover Change Detection:

Image differencing is among the numerous methods that have been developed and used for LULC change detection. Image difference, the difference in the total number of equivalently classed pixels between 2 images, is computed by subtracting the initial state class totals from the final state class totals. A positive value of image difference indicates an increase in class size and a decrease in class size is represented by a negative value. The first step is to get the number of pixels for each class, calculate the area and apply statistical analysis. The magnitude of change is a degree of expansion or reduction in the LULC size. A negative value will present a decrease in LULC size while a positive value will indicate an increase in the size LULC class.

$\mathrm{K}=\mathrm{F}-\mathrm{I}$

where $\quad \mathrm{K}=$ magnitude of change

$\mathrm{F}=$ First Date

$\mathrm{I}=$ Reference Date

$\mathrm{A}=(\mathrm{F}-\mathrm{I}) * 100 / \mathrm{I}$

where $\quad \mathrm{A}=$ Percentage of Change

$\mathrm{F}=$ First Date

$\mathrm{I}=$ Reference Date

\subsection{Statistical Analysis Technique}

Linear Regression analysis was adopted to represent the change in LULC for each class in each year. Linear regression attempts to model the relationship between two variables by fitting a linear equation to observed data. One variable is considered to be an explanatory variable, and the other is considered to be a dependent variable. We will plot Land cover area versus time to visualize the change through linear regression model.

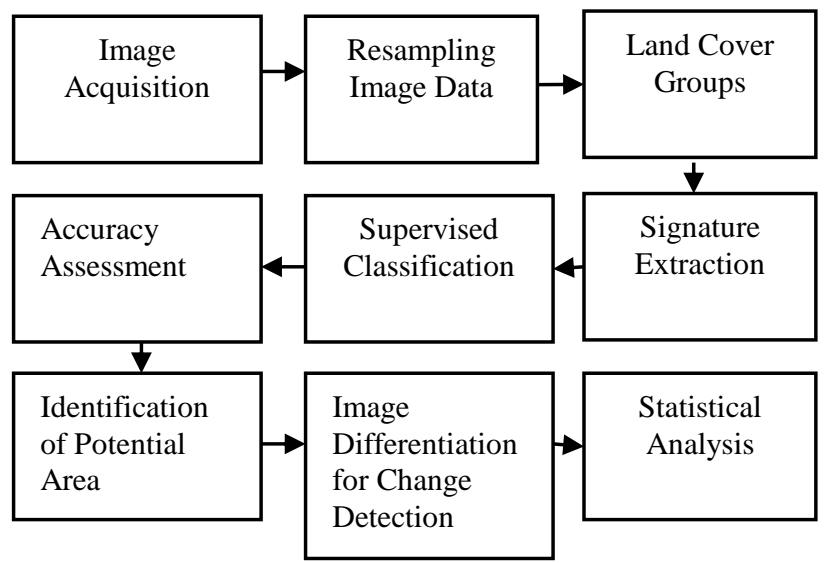

Fig 4: Workflow of Image Classification and Change Detection

\subsection{Lateral Shift/River Channel Migration}

The conventional analogue and advance digital data of MohanaMacheli River are used for the study. Google maps are obtained from open source 'Google Earth' software from this we can obtained the KML layer of mitigation point and this is converted into shape file using ArcGIS. Landsat satellite image is downloaded from USGS site and clipped for our required area and then upscale the data as 3o meter resolution to 10meter resolution using resample tool inside the GIS [Adhikari et al.,2014]. Then all the river is digitized as a polygon shape file and then find its centreline and overlay the all rivers, also calculate the river shift between these years i.e.2009,2011,2013,2015 and 2017 analysis is shown in below diagram.

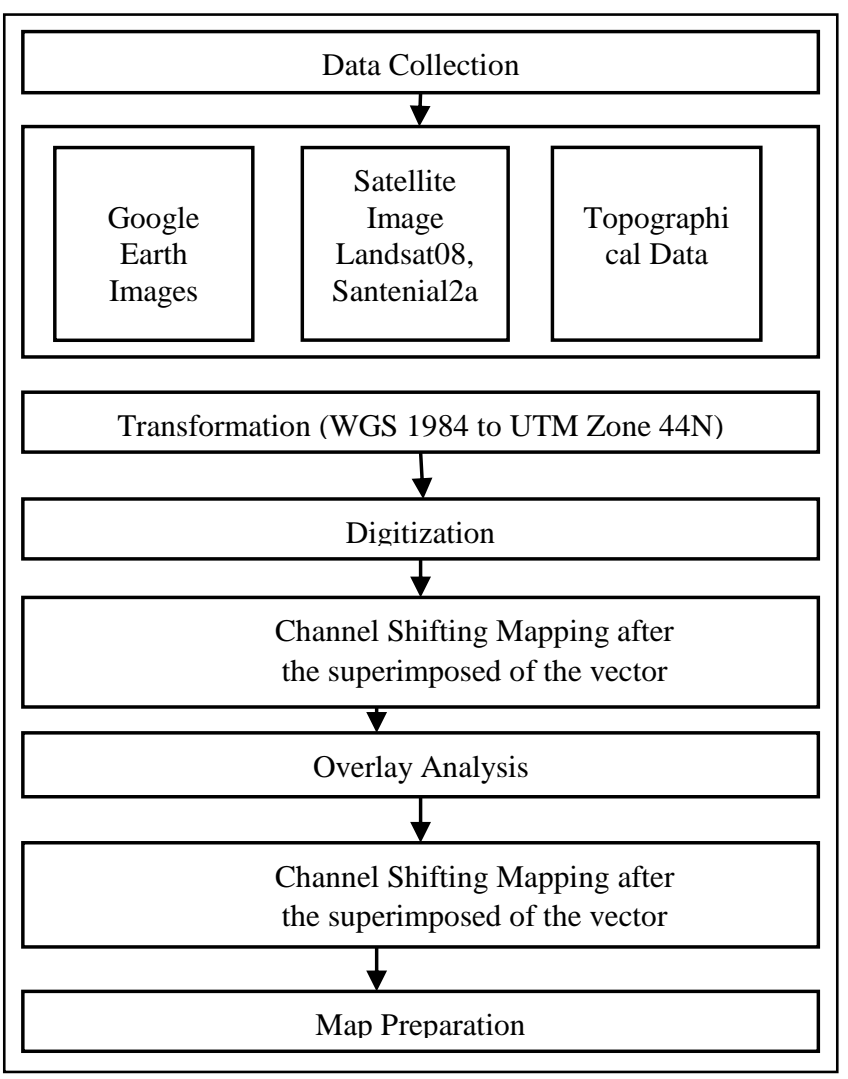

Fig 5: Methodology for the determination of lateral shift of river

\subsection{Cross Sections and Intersections}

Cross Sections data of 2013 from Genesis Technologies is used but this data cannot cover required study area so we generate the cross-section data from River Bankfull Tool which is available in ArcMap. DEM 2013 was used to generate the cross-section for whole study area. Intersection points are generated by intersecting the cross-section data and the river bank lines for all years i.e.2009,2011,2013,2015 and 2017.We choose point as a output data so we obtained the all the intersection point for each river bank for all years.

\section{DATA SOURCES AND TOOLS}

LANDSAT Satellite Images of $30 \mathrm{~m}$ resolution is used for years 2009, 2011, 2013, 2015 and Sentinel Satellite Images of 10 metre resolution for year 2017. ENVI/ArcGIS for feature extraction, image classification and interpretation. 


\section{RESULTS AND DISCUSSION}

\subsection{Potential Sugarcane Cultivation Area}

The sand area in Mohana-Macheli watershed is undertaken by as the potential area for sugarcane cultivation areas to protect the future flooding. Total sand area of each year was calculated along with total sand area in each river for each year of study. The sand cover maps of each year were generated.

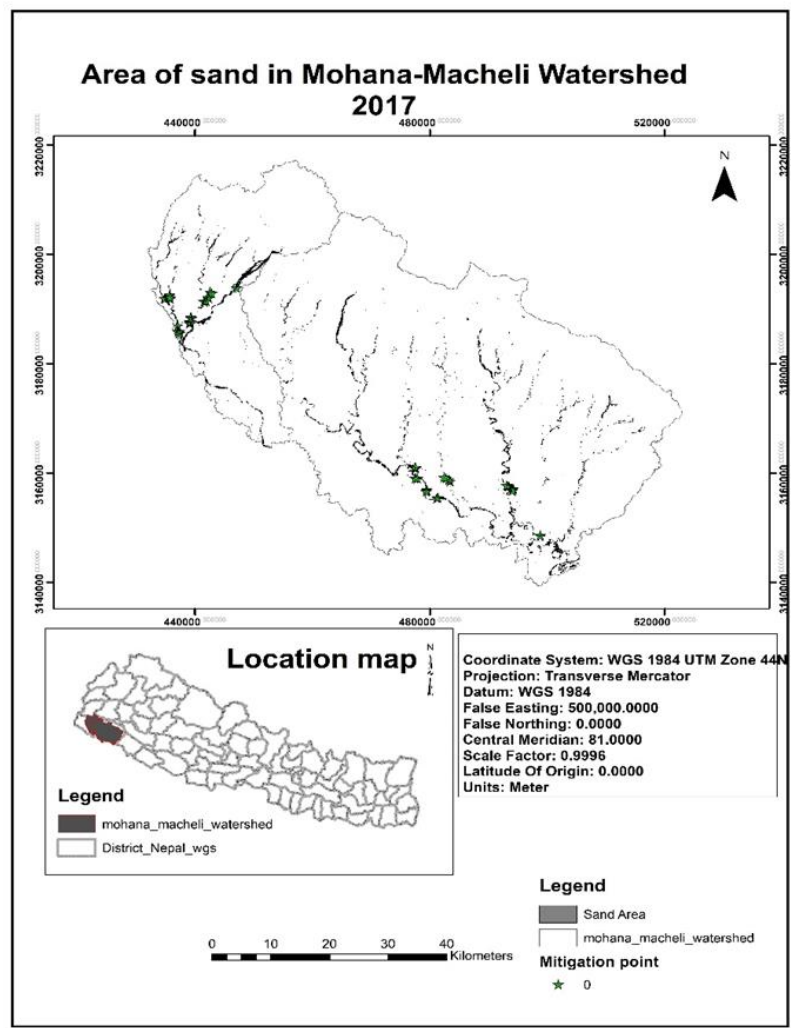

Fig 6: Sand Cover Map of Mohana-Macheli Watershed Nepal for the year 2017

\subsection{Change in Sand Area}

Study shows the sand area has changed significantly during the interval 2013 to 2015 to an increase as high as 163.98 percent. Previous four years and final two-year interval show a stable decrease in sand area. Total sand area change by river is given in the table below with percentage change.

\begin{tabular}{|l|l|l|l|}
\hline \multicolumn{1}{|c|}{ Year } & $\begin{array}{c}\text { Sand Area } \\
\text { Cover (sq. km) }\end{array}$ & $\begin{array}{c}\text { Area } \\
\text { Covered } \\
(\boldsymbol{\%})\end{array}$ & \multicolumn{1}{c|}{$\begin{array}{c}\text { Percentage } \\
\text { Change }\end{array}$} \\
\hline 2009 & 94.092 & 2.505 & \\
\hline 2011 & 35.939 & 0.957 & -61.804 \\
\hline 2013 & 23.508 & 0.625 & -34.589 \\
\hline 2015 & 62.056 & 1.652 & 163.981 \\
\hline 2017 & 24.092 & 0.641 & -61.177 \\
\hline
\end{tabular}

Table 1: Sand Area Change in Mohana-Macheli Watershed from 2009 to 2017
Sand cover variation graph across the watershed during that interval shows the sand to be highest in the year 2009 and least in the year 2013. And the highest change is recorded in the year interval of 2013-2015. The sharp decrease in sand cover from 2009 to 2011 accompanied by low rainfall during that time period. It is seen that sand cover continued to decrease from the year 2011 to 2013 but stated a major increase from 2013 to 2015. Again, the decreasing trend is followed from year 2015 to 2017.

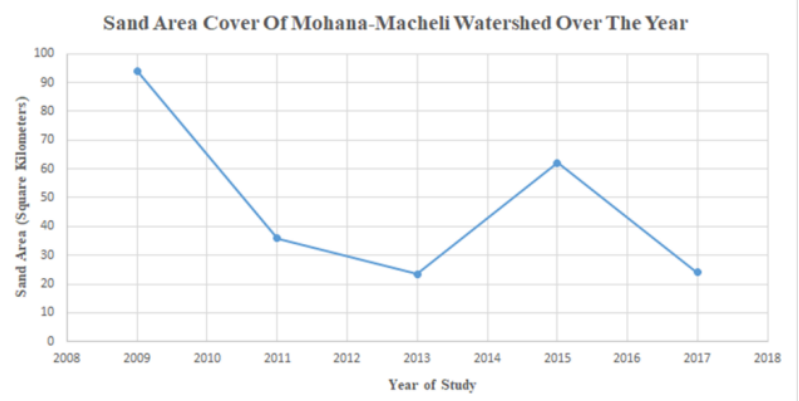

Fig 7: Sand Area Cover of Mohana-Macheli watershed over the year (2009-2017)

A Linear regression model of sand cover change was built to predict the future change in sand area which could have a significant effect on the ecosystem of the watershed:

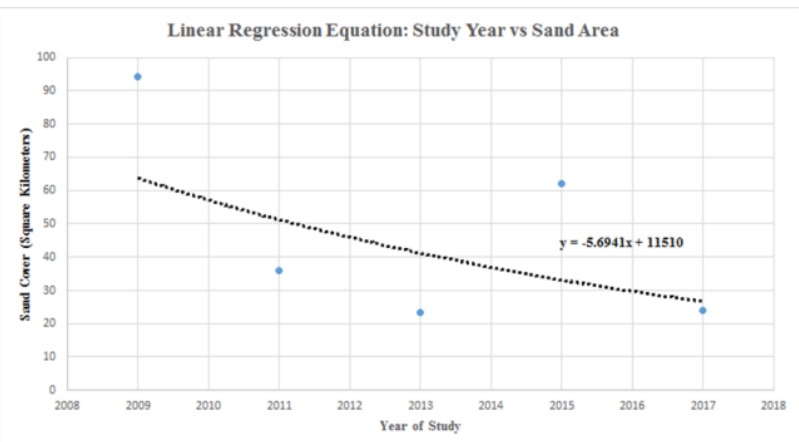

Fig 8: Regression model of sand area change built taking two years interval

A study conducted river-wise change in sand area considering all the major 12 rivers on Mohana-Macheli watershed shows that sand cover in 2009 of each rivers is significantly more than other years supporting our previous discussion. Kateni river has the lowest sand cover as shown by the table below followed by Pathari river.

\begin{tabular}{|l|l|l|l|l|l|}
\hline River/Year & 2009 & 2011 & 2013 & 2015 & 2017 \\
\hline $\begin{array}{l}\text { Banhara } \\
\text { River }\end{array}$ & 2.788 & 0.888 & 0.635 & 0.986 & 0.349 \\
\hline $\begin{array}{l}\text { Godavari } \\
\text { River }\end{array}$ & 1.104 & 0.005 & 0.256 & 0.464 & 0.236 \\
\hline $\begin{array}{l}\text { Guraha } \\
\text { River }\end{array}$ & 2.167 & 0.646 & 0.558 & 1.058 & 0.463 \\
\hline $\begin{array}{l}\text { Kandra } \\
\text { River }\end{array}$ & 9.332 & 2.516 & 2.206 & 5.425 & 3.108 \\
\hline $\begin{array}{l}\text { Karha } \\
\text { River }\end{array}$ & 0.445 & 0.085 & 0.162 & 0.268 & 0.150
\end{tabular}




\begin{tabular}{|l|l|l|l|l|l|}
\hline $\begin{array}{l}\text { Kateni } \\
\text { River }\end{array}$ & 0.983 & 0.130 & 0.050 & 0.320 & 0.202 \\
\hline $\begin{array}{l}\text { Khutiya } \\
\text { River }\end{array}$ & 3.865 & 0.227 & 1.140 & 2.984 & 1.647 \\
\hline $\begin{array}{l}\text { Macheli } \\
\text { River }\end{array}$ & 16.322 & 8.653 & 6.216 & 11.688 & 5.047 \\
\hline $\begin{array}{l}\text { Mohana } \\
\text { River }\end{array}$ & 18.121 & 7.032 & 7.666 & 13.302 & 6.529 \\
\hline $\begin{array}{l}\text { Pathari } \\
\text { River }\end{array}$ & 0.980 & 0.086 & 0.002 & 0.915 & 0.656 \\
\hline $\begin{array}{l}\text { Shivaganga } \\
\text { River }\end{array}$ & 1.628 & 0.169 & 0.150 & 0.945 & 0.354 \\
\hline $\begin{array}{l}\text { Siyali } \\
\text { River }\end{array}$ & 3.517 & 0.374 & 0.681 & 1.921 & 1.081 \\
\hline
\end{tabular}

Table 2: River wise Sand Cover (2009-2017)

\subsection{River Channel Migration}

Analysis of river shifting pattern for all years it is found that there is maximum erosion form 2009-2011 at that time no mitigation measures were applied in the area. In this interval soil erosion was found to be 7295384.676 square meters. Similarly, total land erosion after mitigation (i.e 2015-2017) was found to be 2112785.677 square meters. This result indicates that the mitigation work helped to reclaim a total of 5182598.993 sq. meter area during the year 2009 to 2017. Highest shift in channel is seen in Dodha river where the channel has shifted to as high as 1000 meters from the original path. The channel migration of various rivers has directly affected the land use of the area and has direct effect on the flood plain settlements of the area.

The river banks where the mitigation work was carried out was conserved from being eroded but the banks of same river where no mitigation measures were applied has suffered more erosion. Existing sugarcane cultivated areas are protected from being eroded and the areas where there is no sugarcane cultivation and no mitigation measures are applied have suffered more erosion at the river banks. Remote Sensing digital data give better results than the conventional methods (Sainath P. Aher, 2012). The channel of Mohana and Macheli River shifted to the both bank side, which results obtained by super imposing of topographical maps and Google Map of Mohana and Macheli River. Throughout the study the river stream changes owing to various natural and manmade phenomena. It is done with various analogue and advance digital data study at micro level. In spite of some changes, topographical remote sensing data and GIS studies can help in change detection and other field of fluvial sciences.

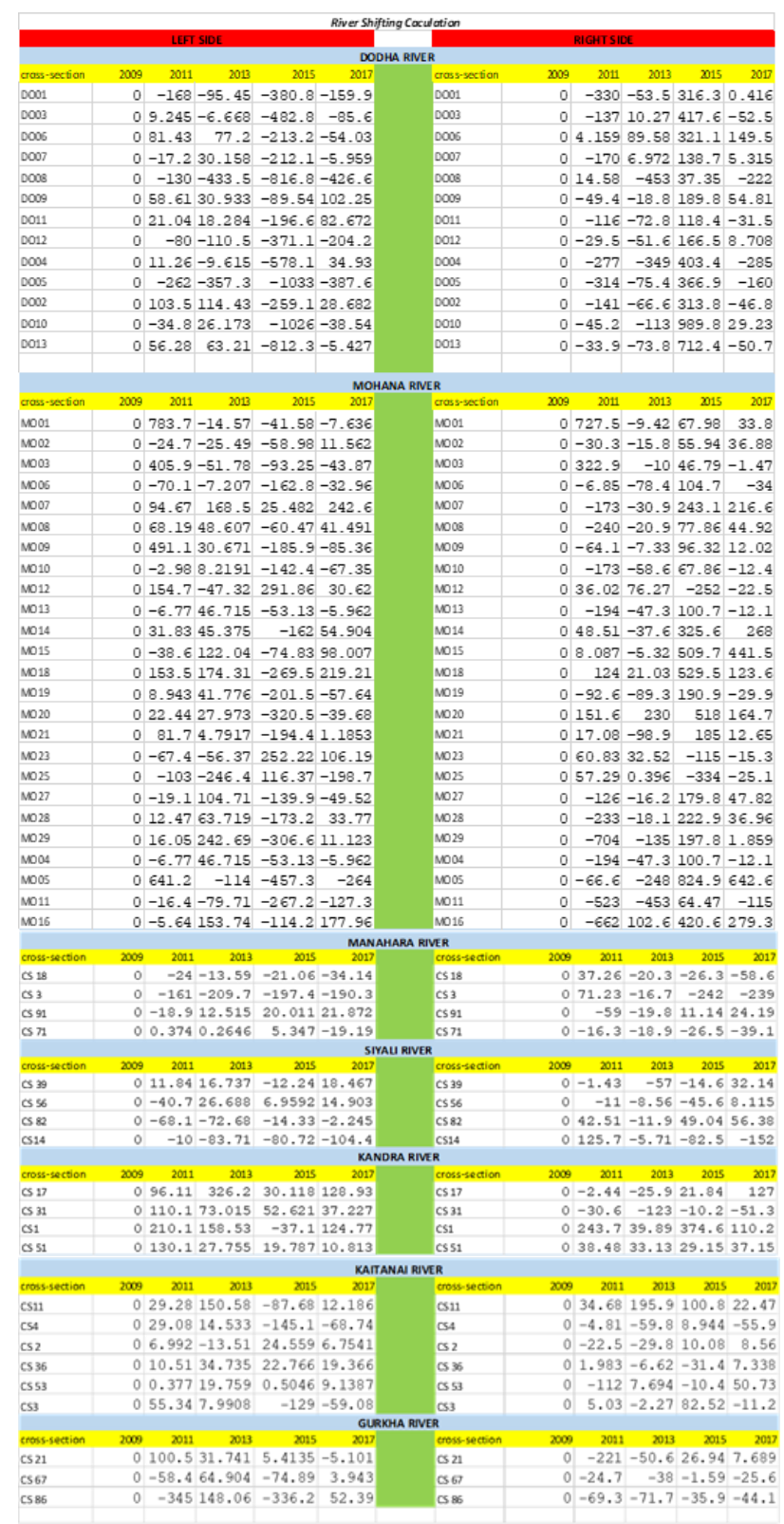

Table 4: Area of River Bank Erosion in different rivers of Mohana-Macheli Watershed

Shift of river bank of Dodha, one of the rivers of the watershed is shown in the graph below, shows 0 value as the boundary and the fluctuations inside and outside from year 2009 to 2017.

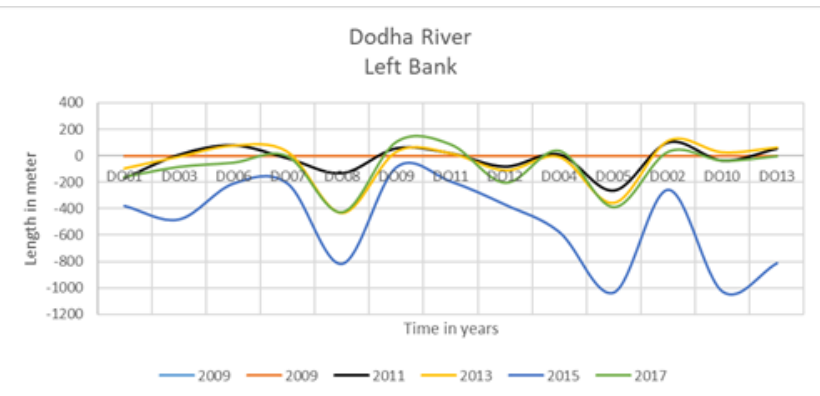

Fig 9: Variation in shifting of left bank of Dodha River inwards and outwards taken 0 as the reference 


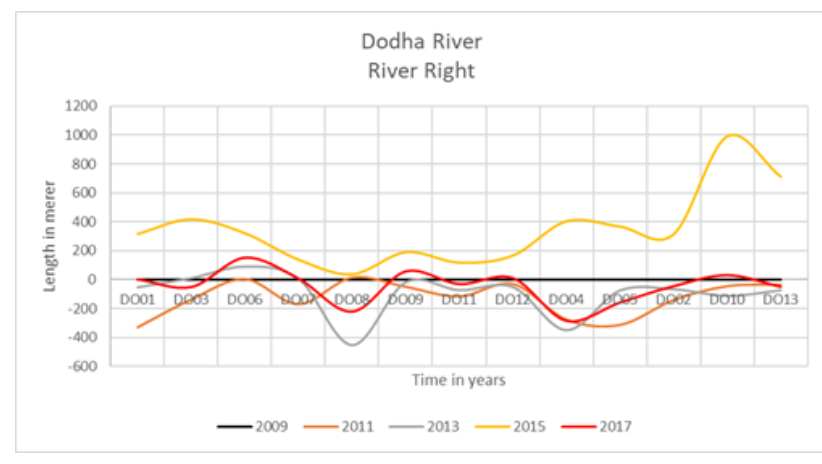

Fig 10: Variation in shifting of right bank of Dodha River inwards and outwards taken 0 as the reference

\section{CONCLUSIONS}

The study is aimed to find out the potential area for sugarcane cultivation as a mitigation measure along the banks of nine rivers in Mohana-Macheli watershed. Sand area is found to be changing disproportionately. Change in sand cover is directly related to rainfall pattern in the area with the highest sand cover in the year 2009 and lowest in 2013. Significant decrease in sand area is observed from 2009 to 2013 and a slight increase in the interval 2013 to 2015 . Sand area is the least in year 2017 with a total area of 24.07 square kilometres which is $61 \%$ decrease than the previous period. Kandra, Mohana and Macheli rivers have the highest sand cover throughout the study period. These three river banks are identified as the most suitable areas to cultivate sugarcane in order to reduce the bank erosion and mitigate the effects of flood whereas Kateni and Pathari river have the lowest amount of sand cover requiring less attention. Remote Sensing digital data gave better results than the conventional methods. The channel of various rivers shifted to the both bank side, which results obtained by super imposing of topographical maps and Google maps. Highest shift in channel is seen in Dodha river where the channel has shifted to as high as 1000 meters from the original path. Shift from original path to 500 meters inwards and outwards is seen in almost every river of the watershed.

\section{REFERENCES}

Adhikary, B. R., 2013. Flooding and Unundation in Nepal: Issues and Concerns: Hydro Nepal, No. 12.

Agarwal, R.P., Bhoj, R., 1992. Evolution of Kosi River fan, India: structural implication and geomorphic significance. Int. J. Remote Sens. 13 (10), 1891-1901.

Alfredsen, S. S. a. k., 2011. Application of HBV model in Hydrological studies of Nepali River Basins: A case study: Hydro Nepal, no. 8. DIPECHO, 2010, Dipecho Newsletter, no. 9.

Allen, J.R.L., 1965. A review of the origin and characteristics of recent alluvial sediments. Sedimentology 5 (2), 89-191. Arogyaswamy, R.N.P., 1971. Some geological factors influencing the behaviour of the Kosi. Rec. Geol. Surv. India $96,42-52$.
Aslan, A., Autin, W.J., Blum, M.D., 2005. Causes of river avulsion: insights from the late Holocene avulsion history of the Mississippi River, U.S.A. J. Sediment. Res. 75, 648-662

D. F. Marble, D. J. Peuquet, 1983. "Geographical information systems and remote sensing" in Manual of Remote Sensing, VA, Falls Church:Amer. Soc. Photogrammetry.

Dulal, D. K. G. a. K., 2013. Determination of threshold runoff for flood warnings in Nepalese rivers: journal of Integrated Disaster Risk Management v. 3(1).

Genesis Consultancy Pvt. Ltd, 2014. Determination of Flood Warning and Danger of Mohana and Macheli River

Hill, Kristina, 2003. A Rapid Land Cover Classification Method for use in Urban Watershed Analysis

M.S.Shrestha, G. A. A., S.R. Bajracharya, R.R. Sharma, 2008. Using satellite-based rainfall estimates for streamflow modelling: Bagmati Basin: Flood RIsk Management.

Mukand S.Babel, S. P. B., Shahriar M.Wahid, Anshul Agarwal, 2013. Climate change and water resources in the Bagmati River Basin, Nepal.

Sainath P. Aher, S. I. ,2012. River Change Detection and Bank Erosion Identification using Topographical and Remote Sensing Data. International Journal of Applied Information Systems (IJAIS), 7 .

Shakya, M. R., 2013. Monsoon rain 17-18 June, 2013 and Floods in Mid and Far Western Regions Disaster Review, DWIDP, v. 20. 